\title{
OS PRIMEIROS DESENVOLVIMENTOS DO CONCEITO HELMONTIANO DE GÁS - PARTE II
}

\section{Paulo Alves Porto}

Programa de Estudos Pós-Graduados em História da Ciência e Centro Simão Mathias de Estudos em História da Ciência, Pontifícia Universidade Católica de São Paulo, Rua Marquês de Paranaguá, 111, Prédio 1, 01303-050 São Paulo - SP

Recebido em 3/5/02; aceito em 5/7/02

\begin{abstract}
EARLY DEVELOPMENTS OF THE HELMONTIAN CONCEPT OF GAS - PART II. This paper focuses on the early interpretations of the concept of gas, originally created by J. B. Van Helmont (1579-1644). Our main interest is on the ideas of English physicians and chemical philosophers of the seventeenth century. Gas was usually associated with the material cause of diseases, with the vital spirit, or with a volatile spirit produced in some kinds of material transformations. As a general trend, however, the authors who did not want to embrace the details of the medico-chemical system proposed by Van Helmont preferred to use more well-known words (such as vapours, exhalations, effluvia, odours, spirits), avoiding the use of the neologism.
\end{abstract}

Keywords: gas; seventeenth-century chemistry; plague.

\section{INTRODUÇÃO}

Em artigo recentemente publicado ${ }^{1}$, abordamos a recepção da idéia original de gás por um médico helmontiano inglês, George Thomson (1619 - 1677). Para Thomson, a causa material de determinadas doenças - como a que foi chamada de "peste" - seria um gás. Ele comparou essa entidade ao gás do enxofre, isto é, ao produto da queima do enxofre, e também explicou algumas observações de laboratório em termos da produção de gases. Observamos, entretanto, que Thomson não estava tão interessado quanto o criador do conceito de gás, J. B. Van Helmont (1579 - 1644), em discutir detalhes acerca da estrutura da matéria. Assim, o gás não teve a mesma relevância no trabalho de Thomson que teve na obra de Van Helmont. No presente artigo, continuamos a investigar as primeiras repercussões do conceito pioneiro de gás no final do século XVII, analisando obras de outros autores desse período.

\section{OS MÉDICOS, A PESTE E O GÁS}

A grande peste que se abateu sobre Londres em 1665 gerou um grande número de obras referindo-se à doença. É comum encontrar nessa literatura a tradicional atribuição da causa da epidemia a alguma espécie de "putrefação" ou "veneno" no ar. Conforme já apontamos em artigo anterior ${ }^{1}$, autores tão diversos como Galeno, Razes, Agricola, Ficino e Paracelso haviam desenvolvido idéias a respeito em suas épocas. Mostramos também como Thomson associou a entidade mórbida responsável pela peste com um gás. Vejamos agora como essa associação foi trabalhada por outros autores, começando por uma obra do farmacêutico William Boghurst.

Boghurst (1631? - 1685) produziu um livro sobre a peste, intitulado Loimographia, cujo manuscrito parecia estar pronto para publicação em 1666; entretanto, não há evidências que haja sido impresso nessa ocasião. Veio a ser publicado, com uma introdução de Joseph F. Payne, em 1894². Nessa obra, Boghurst não demonstrou estar muito preocupado com formulações teóricas. Sua principal preocupação era dar instruções úteis sobre como prevenir a peste, e como curar os pacientes afetados por ela. Entretanto, Boghurst iniciou seu livro procurando mostrar erudição - provavelmente uma estratégia para granjear o res-

e-mail: palporto@pucsp.br peito do leitor, uma vez que ele era um boticário e não possuía título de médico. Assim, Boghurst apresentou uma história das epidemias de peste desde a Grécia Antiga até a Idade Medieval, incluindo também passagens da Bíblia. A seguir, ele passou a especular acerca da causa da peste, confrontando diversas teorias.

O tom geral dessas especulações é de simpatia em relação ao chamado "galenismo", mencionando os humores e as qualidades primárias, as tradicionais técnicas terapêuticas de purgações, e a composição de medicamentos vegetais. Todavia, Boghurst também abraçou diversos aspectos das tendências mais "modernas" da época. Ele elogiou Thomas Willis e Robert Boyle, e inclinou-se na direção da filosofia corpuscular, citando Lucrécio, Gassendi, Descartes, entre outros. Boghurst também cita Van Helmont, e demonstrou respeitar os "remédios químicos" (isto é, aqueles preparados com técnicas alquímicas de laboratório em geral, em particular os compostos de origem mineral). Boghurst concordava com os "médicos químicos" em relação a um ponto muito importante no tratamento da peste: para ele, seria inconveniente fazer sangrias no paciente infectado, assim como submetê-lo a outras purgações muito fortes.

Quanto à causa da peste, Boghurst afirmou que se trataria de um veneno no ar. Para ele, a essência da peste estaria localizada num veneno específico, feito de corpúsculos "muito sutis e invisíveis", contrário aos princípios vitais do ser humano ${ }^{3}$. Boghurst acreditava que esses "vapores venenosos e eflúvios pestíferos, que viciam e corrompem o ar"4 seriam provenientes da terra; e fez a seguinte analogia para justificar sua tese:

que existem tais vapores destrutivos aos princípios da vida encerrados nas cavidades da terra deve ser evidente para qualquer um que reflita sobre aquelas névoas que são freqüentes em minas de carvão e outras, que num instante sufocam os espíritos daqueles que se dedicam a esse trabalho, e extinguem a lâmpada da vida ${ }^{5}$.

É interessante notar que Van Helmont também chamou a atenção para o perigo representado pelas substâncias presentes no ar das minas subterrâneas, identificando-as com um gás mórbido ${ }^{6}$. Mais adiante, Boghurst incluiu uma citação a Van Helmont, para concordar com a interpretação dada pelo médico belga quanto à causa material da peste. Boghurst, assim, oferece sua interpretação para o gás helmontiano: 
Mas, pelo que foi dito anteriormente, podemos bem resolver com Helmont que a matéria da peste é nada mais do que fracidum gas terrae $^{7}$, como ele o chama; isto é, como ele próprio explica, silvester spiritus veneno tinctus ${ }^{8}$, ou um vapor venenoso que se ergue da terra, e esta é a opinião de diversos médicos eruditos ${ }^{9} .$.

Para entendermos a citação de Boghurst, precisamos lembrar que Van Helmont se referia a alguns gases como "espíritos selvagens", isto é, incoercíveis - uma forma sutil de matéria que não poderia ser contida em frascos, pois tenderia a escapar deles ou mesmo a provocar uma explosão (como no caso do gás formado pela interação entre salitre, enxofre e carvão, os componentes da pólvora negra $)^{10}$. Conforme podemos observar, Boghurst, tentando esclarecer a idéia de Van Helmont, finalmente traduz gas como "vapor" - mas ele poderia ter usado outras palavras, como se pode ver em outras passagens. Numa delas, Boghurst escreveu que a peste se origina com "eflúvios malignos, ou fumos, ou vapores", liberados da terra para o $\mathrm{ar}^{11}$. Ou ainda, conforme ele sumarizou ao final do capítulo 1:

A peste é uma exalação extremamente sutil, peculiar, insinuante, venenosa e deletéria, que se origina da maturação do fermento das fezes da terra, extraída para o ar pelo calor do sol, e espalhada de um lugar a outro através dos ventos; e na maioria das vezes agredindo corpos apropriados gradualmente, mas algumas vezes imediatamente ${ }^{12}$.

Aqui, o que antes fora referido como gás ou vapor, é referido como "exalação". Essa multiplicidade de termos pode ser vista também numa outra situação: quando Boghurst discute o tipo de matéria que produz as marcas características da peste no corpo do doente. Para ele, essas marcas teriam origem em substâncias aeriformes espalhadas pelo organismo, para as quais ele utiliza indistintamente termos como "eflúvios", "vapores" ou "exalações"13.

Outro exemplo da associação entre o termo helmontiano gás com uma entidade mórbida pode ser encontrado em The Principles of the Chymists of London, publicado em 1676. Este livro é uma espécie de manifesto, ou declaração de princípios, de um grupo de "médicos químicos" que se opunham ao "Royal College of Physicians", e que se teriam proposto a publicar algumas opiniões consensuais. O texto inclui, evidentemente, críticas ao galenismo, e expõe teorias para as doenças e curas de clara inspiração helmontiana. Os autores procuraram expor a idéia de que o corpo humano seria governado por um "espírito vital", de cujo comportamento dependeriam a saúde e a doença:

assim como a vida, ou a saúde, é mantida pelo princípio ou espírito da vida não perturbado; assim a morte, ou uma doença (seu pródromo ou precursora), é produzida pelo erro, exorbitância, ou indignação daquele espírito ... Toda doença originalmente é imaterial, e no espírito, embora seja adquirida pelo contato com um mal material ${ }^{14}$..

Vale notar que, ao longo do texto, esse "espírito vital" em nenhum momento é chamado de archeus, como fora denominado por Van Helmont. Seguindo a teoria mencionada acima, os autores procuraram mostrar como o "espírito vital" determinaria a doença; e, nesse contexto, citaram o gás como uma entidade que, devido à sua afinidade com o "espírito vital", seria particularmente perigosa:

A picada de um espinho, em respeito a sua magnitude ou forma, não pode racionalmente ser considerada como capaz de produzir mais agonia do que uma facada ou corte; e, no entanto, vemos que o Espírito fica mais enfurecido ... Sabe-se, experimentalmente, que a mordida de um homem acometido de raiva é mais venenosa, e curada com maior dificuldade, do que a mordida de um cachorro louco; todavia, ambos os males são de dimensão e forma semelhantes. Assim também o Gás de um veneno mata mais rapidamente do que o mesmo veneno tomado em substância ${ }^{15}$.

A idéia, expressa aqui, é a de que substâncias semelhantes poderiam provocar reações diferentes sobre o "espírito vital". Um espinho, embora atinja uma extensão menor do corpo, provocaria uma reação mais violenta do que um corte ${ }^{16}$. O veneno que provoca a raiva (ou hidrofobia) interagiria mais fortemente com o "espírito vital" quando proveniente de um ser humano do que quando proviesse de um cão; afinal, o "espírito vital" o estaria recebendo de uma fonte mais semelhante a si mesmo. Finalmente, o gás de um veneno seria mais letal que o mesmo veneno "em substância", ou seja, "coagulado" ou fixo. Podemos pensar num exemplo retirado de Van Helmont, como o do gás dos minerais inspirado pelo espagirista em seu laboratório ${ }^{17}$. A explicação, nos termos da teoria, é clara: o gás seria uma forma menos "concreta" da substância, e por isso mais semelhante ao "espírito vital" - o qual, dessa forma, poderia interagir mais rápida e profundamente com o gás do que com o corpo que daria origem a este. A palavra gás, entretanto, só é usada neste exemplo em todo o livro. Os autores falam ainda de uma substância de natureza aeriforme que distribui a vida por todo o organismo, servindo como uma espécie de intermediário entre o "espírito vital" e a parte material do corpo humano. Essa entidade corresponderia ao que Van Helmont chamou gás vital; os autores desse opúsculo, no entanto, preferiram usar as denominações ather, ou ar interno. Os autores, portanto, parecem preocupados em divulgar as idéias helmontianas, mas sem recorrer a tantos neologismos quanto o mestre belga. Poderia ser uma estratégia para facilitar a compreensão do leitor e, ao mesmo tempo, facilitar a relação com outras idéias médicas tradicionais (como o corpus hipocrático, por exemplo) - ampliando o espectro de possíveis simpatizantes.

A idéia de gás vital, por sua vez, pode ser encontrada em um importante glossário de termos relacionados à medicina, publicado no final do século XVII. Seu compilador foi um médico de origem holandesa, Stephen Blancard, ou Blankaart. A primeira edição inglesa, A Physical Dictionary, é datada de 1684. O prefácio dessa edição é acompanhado por uma lista com o nome dos autores cujas obras foram consultadas para a confecção do dicionário. A eclética relação, em ordem alfabética (incluindo, por exemplo, Avenzoar, Aristóteles, Boyle, Descartes, Celso, Galeno, Van Helmont, Malpighi e Vesálio), contém cerca de cento e setenta nomes, seguidos pela expressão "e muitos outros". Nessa edição, contudo, não se encontra o verbete "gás". Este será incluído na terceira edição, intitulada The Physical Dictionary e publicada em 1697, em cuja folha de rosto se anuncia que esta edição conta com "a adição de mais de mil termos da arte, e suas explanações”. Eis como Blancard se referiu ao gás:

Gás, um termo usado por Helmont, e significa um espírito que não coagulará; ou o espírito da vida, um bálsamo que preserva o corpo da corrupção ${ }^{18}$.

Percebe-se que o autor contemplou, em sua curtíssima definição, duas dimensões do conceito helmontiano. Por um lado, o da observação em laboratório, que definia o gás como um "espírito" não coagulável, ou seja, que não pode ser facilmente condensado como os vapores comuns ${ }^{19}$. É a idéia do gás incoercível, ou silvestre. Por outro lado, Blancard mencionou o gás presente no organismo, responsável pela "irradiação" dos poderes vitais do archeus influus por todo o corpo. Trata-se do gás vital, ao qual o próprio Van Helmont se referia como um "bálsamo que preserva da corrupção". Curiosa- 
mente, Blancard não faz menção ao gás como possível causa material de doenças, que era uma das interpretações mais comuns entre os médicos helmontianos da época.

\section{GEORGE STARKEY E O GÁS}

O médico químico George Starkey (1628 - 1665) está entre os principais seguidores de Van Helmont. Um extenso estudo a seu respeito foi publicado por William Newman ${ }^{20}$, e novos estudos continuam a ser feitos por esse historiador da ciência, em colaboração com Lawrence Principe. Starkey parece ter sido um dos médicos químicos que melhor compreendeu as teorias de Van Helmont, o que transparece em seus escritos - muito menos obscuros que os do mestre belga - , e no modo como Starkey relacionava as teorias a suas observações práticas.

Starkey enalteceu o uso do "verdadeiro, claro e límpido espírito do enxofre" conforme fora recomendado por Van Helmont. Starkey procurou explicar a ação desse remédio: sua acidez limparia as impurezas que, aderidas ao estômago, atrapalhariam a digestão; “e, por meio de seu Gás sulfuroso, conservariam da corrupção putrefativa os alimentos e bebidas ingeridos". Essas seriam as causas da longevidade de quem seguisse as recomendações sugeridas por Van Helmont ${ }^{21}$.

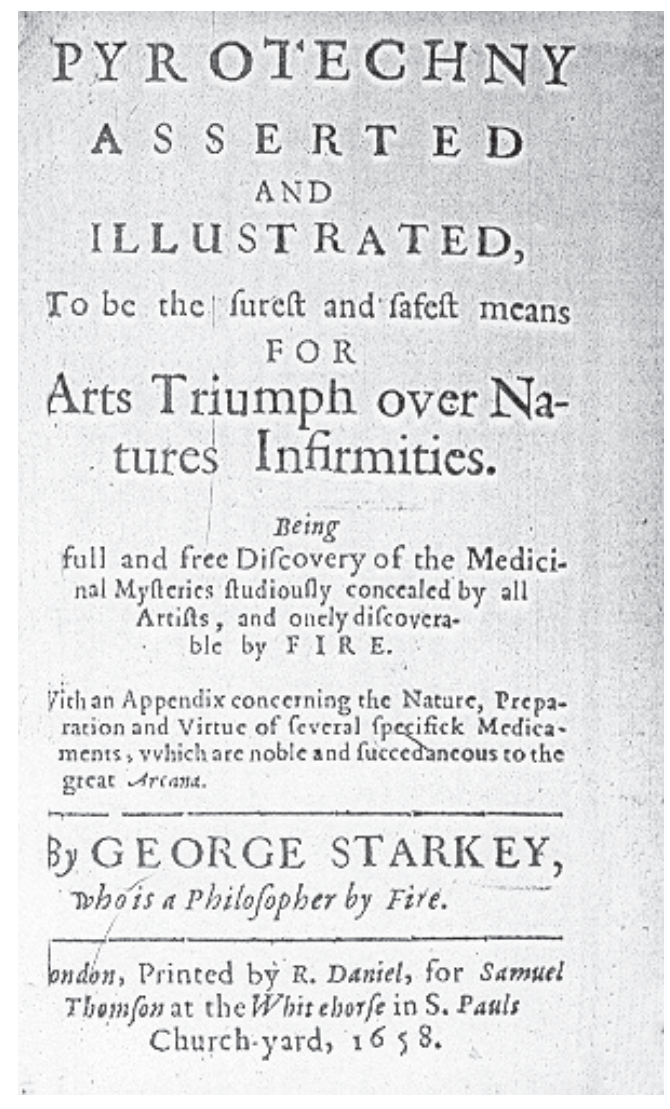

Figura 1. Folha de rosto do livro Pyrotechny Asserted and Illustrated (1658), no qual George Starkey ressalta as virtudes médicas do gás sulfuroso

Ainda mais interessante, porém, é ver como Starkey aplicou a teoria helmontiana da matéria para explicar fenômenos que ele observou. Em seu livro sobre o alkahest ${ }^{22}$, publicado postumamente, Starkey descreveu a formação de um "coagulado" branco quando misturou um "licor destilado da urina" com um "espírito ácido".
Para explicar esse efeito, que Starkey considerou pouco usual nas circunstâncias, ele recorreu a uma explicação análoga à usada por Van Helmont para explicar a formação de gelo quando se resfria água:

\begin{abstract}
A partir dos testemunhos deste agudíssimo e verdadeiramente adepto filósofo pelo fogo [i.e., Van Helmont], coloquei minha mente a considerar o fenômeno em si, e descobri ser um objeto de grande admiração. Minha experiência convenceu-me de que era um coágulo anômalo ... O espírito ácido, tentando, através de sua corrosividade, destruir este espírito tenro, que é extraordinariamente volátil e voador; este, para melhor defender-se, assume a forma de um corpo coagulado (assim como a água, para resistir à força ativa do frio que a transformaria em Gás, incrustra-se, por sua própria ação, em um gelo) ${ }^{23}$.
\end{abstract}

Para bem compreendermos a referência de Starkey, precisamos lembrar das idéias de Van Helmont acerca do resfriamento da água. Para o médico belga, o frio intenso transformaria a água em gás d'água, pela divisão daquela em partículas mínimas. Isso ocorreria naturalmente na alta atmosfera, que seria um lugar muito frio, e onde a água chegaria em forma de vapor ou mascarada por algum fermento (ou seja, na forma de algum outro gás ou vapor). A água líquida, se estivesse parada, entretanto, tenderia a resistir a essa transformação em gás d'água - e faria isso adquirindo a sólida conformação de gelo. Esse mecanismo aparentemente complicado servia para Van Helmont explicar as sucessivas transformações de seu elemento primordial - água - e também para justificar como o frio poderia ter dois efeitos tão diferentes sobre essa substância (transformação em gelo ou em gás d'água) ${ }^{24}$. Starkey demonstrou haver compreendido o modelo proposto por Van Helmont, e acreditou haver encontrado outro fenômeno com análogo comportamento.

Em seu caderno de laboratório, e em sua correspondência com Robert Boyle (1627 - 1691), Starkey também menciona o gás algumas vezes. Starkey fez experimentos com diversos óleos vegetais, que registrou num caderno - o qual surpreende pela organização e detalhamento das observações realizadas. Ao tomar notas sobre um experimento envolvendo óleo de terebintina, Starkey escreveu:

Observo, finalmente, que a quantidade de óleo não é aumentada em nada por sua destilação destes corpos, muito embora ele possa exibir uma boa alteração em cor, odor, ou sabor. Acrescento que a destilação ocorre junto com muito gás silvestre, o qual no entanto pouco ou nada aquece o vidro ${ }^{25}$.

Ou seja, Starkey chama de gás silvestre a um "espírito" liberado em laboratório durante uma destilação. Numa de suas cartas a Boyle, na qual trata principalmente de algumas especulações teóricas a respeito do alkahest, Starkey menciona de passagem um outro tipo de gás:

Você vê que o trovão terrestre, o gás ventoso, e o calor e o frio respondem à vontade do artífice. Você vê que que há artes pelas quais um grande calor pode ser produzido a partir do espírito do vitríolo através de uma pequena gota de água fria adicionada a $\operatorname{ele}^{26} \ldots$

Gás ventoso foi a expressão que Van Helmont usou algumas vezes para se referir ao ar comum (que, no entanto, seria de natureza bem diferente dos demais gases). A idéia geral de Starkey neste fragmento parece ser a de que o filósofo químico seria capaz de produzir em laboratório fenômenos semelhantes ao que se observa na Natureza, como a produção de ventos ou calor. 
A menção mais curiosa ao gás na obra de Starkey, a nosso ver, encontra-se numa outra carta a Boyle. Ela revela a freqüente troca de correspondências - e mesmo de pequenos presentes - entre os dois no período. Juntamente com uma carta anterior, Boyle havia enviado uma torta a Starkey (que dizia retribuir o gesto enviando agora algumas frutas provenientes da Nova Inglaterra). Por algum motivo, entretanto, a torta se extraviara no caminho, e Starkey não a recebera; ele, então, fez uma brincadeira sobre o incidente, "explicando" o desaparecimento da torta em termos químicos:

Eu culpo o frio do inverno, que tem se mantido por tão longo espaço de tempo, por sua torta haver-se convertido em gás invisível; por isso parece que sua desculpa, na qual você advertiu acerca da qualidade dela, era cheia de modéstia: pois devido à espiritualidade dela, toda ela sem dúvida transformou-se por si mesma em ar! ${ }^{27}$

Observa-se a intimidade de Starkey (e, provavelmente, também de Boyle) com a teoria helmontiana acerca da produção de gás d'água - de que o frio intenso poderia destruir os fermentos que dariam a especificidade a um corpo, reduzindo tudo a água elementar, na forma de gás - a ponto de Starkey utilizar-se dela num chiste. Isso demonstra o excelente domínio que Starkey tinha das teorias de Van Helmont, e a originalidade de seu pensamento em aplicá-las a diferentes contextos ${ }^{28}$. Vale ressaltar, finalmente, que não encontramos nenhuma passagem em que Starkey mencione o gás como causa material de doenças. Tal fato não deixa de ser algo surpreendente, em vista da amizade que o já mencionado Thomson diversas vezes afirma ter com Starkey, e dos elogios que Thomson lhe faz - referindo-se a ele, por exemplo, como "aquele excelente e experto químico, e legítimo médico, Dr. Starkey"29. Em outra passagem, Thomson foi ainda mais enfático em sua avaliação de Starkey, "[e]ste bravo homem (que fez, atrevo-me a dizer, mais boas obras do que todos os Galenistas da Inglaterra juntos $)^{30}$..." Ainda assim, Starkey parecia não compartilhar da ênfase que Thomson colocava nos gases como entidades mórbidas, dando mais atenção ao seu papel na teoria da matéria.

\section{ROBERT BOYLE E O GÁS}

Boyle, por seu turno, rejeitou a idéia de gás como fora proposta por Van Helmont - apesar da importante influência do médico belga na formação do pensamento químico de Boyle. Tomemos como exemplo o uso dos "fumos de enxofre" como conservante, que parece ter sido reconhecido como uma prática útil em sua época, e associado ao gás helmontiano. Boyle raramente usa a palavra "gás" em suas obras; e, em pelo menos duas oportunidades, sua intenção era condenar o uso não crítico desse termo ${ }^{31}$. Conforme apontou a historiadora da ciência Alfonso-Goldfarb ${ }^{32}$, Boyle aparentemente não compreendeu o conceito de gás como Van Helmont o propôs. Boyle não teria compreendido a distinção estabelecida por Van Helmont entre gás e ar. Quando se referia a substâncias que Van Helmont chamaria de gases (como o produto da interação entre vinagre destilado e coral pulverizado), Boyle usava nomes como "ar factício" ou "ar artificial" ${ }^{33}$. Entretanto, ao falar da conservação de vinhos e outros produtos, Boyle recorreu à palavra "gás" e relacionou-a com os "helmontianos":

Que tais vapores subterrâneos se misturarão facilmente com líquidos, e os imbuirão com suas próprias qualidades, pode ser inferido a partir do experimento em que se mistura o gás (como o chamam os helmontianos) - ou os fumos pouco coaguláveis de enxofre aceso e extinto - com vinho, o qual é dessa maneira longamente conservado. E, em outro lugar, mencionei como incorporei esta fuma- ça a outros líquidos, tendo observado que suas operações são notáveis $^{34}$.

Em outro tratado, Boyle reconheceu que esta técnica de conservação não fora inventada por ele, e a atribuiu a Van Helmont:

\begin{abstract}
... o modo mais efetivo que já pratiquei, Pyrophilus, para preservar ... licores e sucos [de plantas], é destra e suficientemente impregnálos com fumos de enxofre ... Se você o praticar com cuidado, sentir-se-á, talvez, obrigado a me agradecer pela descoberta - embora um leitor atento possa encontrá-la, de modo não obscuro, sugerida nos escritos de Helmont ${ }^{35}$.
\end{abstract}

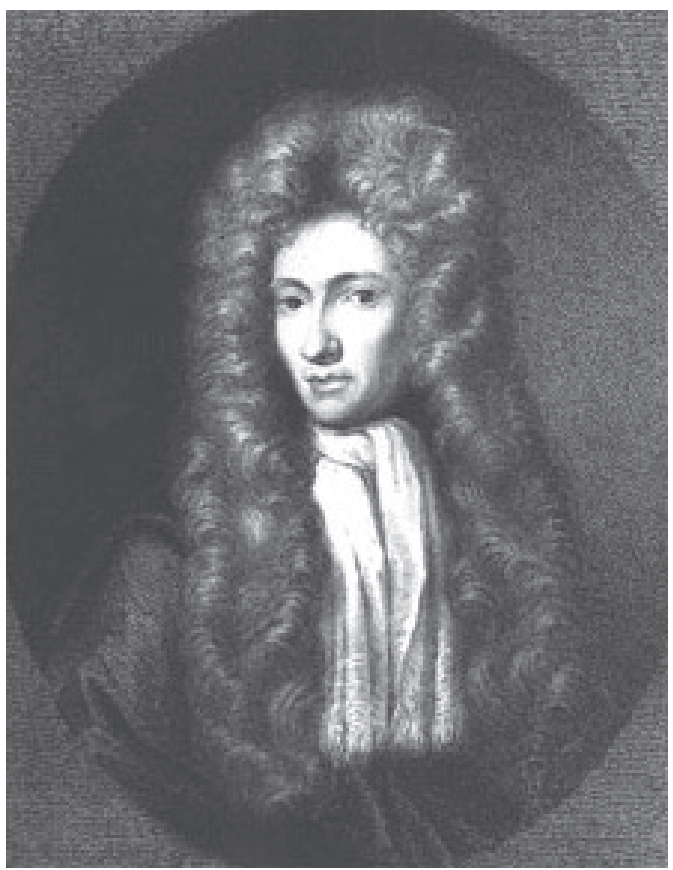

Figura 2. Robert Boyle (1627-1691)

Outra fonte em que Boyle menciona a palavra é em sua correspondência com o então secretário da "Royal Society", Henry Oldenburg. Em algumas das cartas trocadas entre eles, percebe-se que ambos manifestavam interesse em conhecer essa entidade, geralmente associada ao nome de Van Helmont ou de seus seguidores mais próximos. Em uma das cartas, Oldenburg pede a opinião de Boyle acerca do assunto:

Eu ficaria muito satisfeito em ouvir seus pensamentos no que concerne ao Gas sulphureum, que eu mencionei anteriormente a você; bem como maiores informações sobre as dimensões de seu vidro ustulatório, se você as tiver ${ }^{36}$.

Em sua resposta, Boyle escreveu:

Tenho, de um modo geral, uma opinião muito boa acerca da fumaça ou Gás (como Helmont diz) do enxofre, tendo tido alguma experiência de sua virtude para conservar licores e impedir a sua putrefação ${ }^{37}$.

Tal prática parecia não ser incomum, pois Oldenburg em seguida mencionou outro filósofo químico que também recomendava essa técnica de conservação: 
Humildemente agradeço-lhe por sua opinião acerca do Gás helmontiano, o que para mim é um não pequeno encorajamento para continuar a utilizá-lo, do modo como é preparado pelo D[r?]. Poleman ${ }^{38}$.

Observa-se, pois, que o uso que Boyle faz do termo gás é bastante restrito, quando não desfavorável.

Uma fonte importante para a compreensão de algumas idéias que circulavam entre os filósofos naturais do final do século XVII e início do XVIII - especialmente os de inclinação mecanicista, como Boyle - é o Lexicon Technicum de John Harris, publicado em 1704. Ao escrever sobre termos como "ar", e outros correlatos ou referentes à química, as principais autoridades a que Harris recorreu foram Boyle e Hooke. Vejamos o que Harris escreveu sobre o gás:

GÁS, uma palavra usada por Van Helmont, e parece designada para significar, em geral, um espírito não capaz de ser coagulado. Mas ele o usa livremente em muitos sentidos; pois ele chama o princípio vital no homem, Gas Vitale; aquela névoa sulfurosa ou arsenical, ou qualquer outra névoa nociva que é encontrada em algumas minas, ele chama de Gas Pingue Sulphureum. Mais ainda, às vezes ele chama o ar de Gas Ventosum, assim como a água de Gas Salium; e, em resumo, fala muito ininteligível e inconsistentemente sobre isso, como é o costume dos químicos em outras coisas ${ }^{39}$.

Percebe-se que a principal crítica de Harris a Van Helmont seria a inconsistência do médico belga quanto ao uso da palavra criada por ele mesmo. Harris pareceu ter dificuldade em aceitar a integração entre as teorias sobre a estrutura da matéria e as teorias médicas de Van Helmont, ao menos no que se refere ao uso do termo gás. De qualquer forma, o objetivo de Harris aqui seria criticar a linguagem obscura dos químicos, defendendo o que os filósofos mecanicistas acreditavam ser uma clara explicação para a Natureza, em termos de partículas em movimento. Consultando outros verbetes, vemos que havia numerosos outros termos para descrever manifestações materiais que Van Helmont poderia considerar como gases: exalações, vapores, eflúvios, odores, espíritos.

\section{CONCLUSÕES}

Observamos que, entre os filósofos químicos mais preocupados com os aspectos médicos do pensamento helmontiano - como foi o caso de Thomson - o conceito de gás foi mais fortemente associado com a causa material de doenças (que a tradição atribuía a uma morbidez do ar) ou com o gás vital, uma espécie de "espírito" existente no sangue que preservaria a vida nas partes mais recônditas do organismo. Poucos foram os que, como Starkey, adotaram as teorias de Van Helmont sobre a estrutura da matéria com maior profundidade, a ponto de discutirem o mecanismo de formação do gás em escala microscópica. Esse processo, tal como fora proposto pelo médico belga e adotado por Starkey, aliás, poderia até se encaixar dentro de visões mecanicistas dos fenômenos naturais. Afinal, Van Helmont falava que a formação de gás envolvia a divisão dos corpos em partículas mínimas; em particular, no caso da formação do gás d'água na alta atmosfera, o corpo da água seria dividido devido à sua penetração por diminutas partículas de ar (que para Van Helmont seria um elemento à parte). Ainda assim, pensadores de tendências ao corpuscularismo - e Boyle seria um caso exemplar - viam com reservas a idéia de gás. Boyle, particularmente, era contra o uso não crítico de novos termos (como era prática comum entre os filósofos químicos, desde Paracelso), e incluiu o gás entre eles. Para designar substâncias misturadas ao ar, Boyle usou termos como eflúvios, exalações, vapores, etc.
Um médico que estivesse interessado apenas nos aspectos mais práticos da medicina helmontiana, como suas indicações terapêuticas, e sua teoria geral para a doença e a cura, poderia fazer uso da palavra gás - como um símbolo de sua filiação à nova corrente médica, cuja novidade ficava explícita por um vocabulário que podia incluir ainda termos como archeus, blás ou alkahest. Ou, por outro lado, poderia não incluir o novo termo gás, substituindo-o por palavras mais familiares, como espírito ou exalação - da mesma forma que alguns médicos adotaram uma teoria para as doenças claramente helmontiana, mas não usaram a palavra-chave archeus, preferindo expressões como "espírito vital", "poder vital", "força vital” ou equivalentes. Isso era possível porque, não abordando os detalhes da teoria de Van Helmont para a matéria, nem pretendendo explicar todo o espectro de fenômenos a que o mestre belga se propôs (que incluía fatos que hoje chamaríamos de meteorológicos, geológicos, físicos, químicos, médicos), um médico podia muito bem prescindir de alguns dos novos conceitos ou nomes.

Por outro lado, alguns dos novos filósofos naturais podiam se impressionar com a acurada capacidade de observação de Van Helmont, bem como com suas engenhosas experiências em laboratório. O próprio Boyle confessava sua admiração pela habilidade experimental do médico belga. Entretanto, a teoria de Van Helmont para a matéria (e também para a doença e cura) tinha no archeus uma espécie de "espírito" ou "força" imanente nos corpos - sua figura central, e incluía alguns tipos de ação por simpatia, irradiações não materiais, etc., que eram incompatíveis com um corpuscularismo mais radical. Assim, também entre estes, o conceito de gás encontrou barreiras. Para se referir a fenômenos observáveis, como os produtos de transformações químicas ou evaporações, qualquer filósofo natural podia usar palavras que já se encontravam em uso (vapor, fumo, espírito, eflúvio, exalação, névoa, fumaça), sem ter necessidade de um novo termo. A adoção da palavra gás implicaria, nessa época, na aceitação de uma carga de teorias helmontianas que os filósofos naturais de inclinação mecanicista não podiam aceitar, e que muitos dos próprios médicos que diziam seguir Van Helmont não estavam interessados em carregar.

Após a derrocada da corrente médica que preconizava uma reforma médica radical baseada no helmontianismo, a palavra "gás" ficou relativamente em desuso, até ser definitivamente incorporada ao vocabulário da química moderna do final do século XVIII. Na Inglaterra, os chamados "químicos pneumaticistas" setecentistas, como Stephen Hales, Joseph Black e Henry Cavendish, continuaram a usar o termo genérico "ar". Num local onde o helmontianismo florescera, a palavra gás havia sido abandonada. Hales preocupouse em extrair o "ar" contido em substâncias de origem vegetal e animal; mas acreditava que se tratava do mesmo "ar" em todos os casos, cujas partículas serviriam para manter a coesão dos corpos, e estava interessado apenas em cuidadosas medidas quantitativas dos volumes de "ar" em cada amostra. Black e Cavendish, no entanto, já demonstravam a existência de diferentes "ares", com propriedades químicas qualitativamente diferentes. Assim, o uso do termo "gás" somente foi incorporado à nova nomenclatura da química do final do século XVIII, quando uma nova abordagem qualitativa teria sido capaz de se "casar" com uma abordagem quantitativa de tradição mecanicista - o que implicava numa nova visão a respeito da matéria e de suas transformações, mas já muito distante do panorama conceitual helmontiano ${ }^{40}$.

\section{AGRADECIMENTOS}

À FAPESP (Fundação de Amparo à Pesquisa do Estado de São Paulo) pela concessão de bolsas de pós-doutorado (Processos nos. 98/06209-7 e 01/06360-1), junto à "Johns Hopkins University" 
(Baltimore, EUA) e à Pontifícia Universidade Católica de São Paulo, o que possibilitou a elaboração deste trabalho.

\section{REFERÊNCIAS}

1. Porto, P. A.; Quim. Nova 2001, 24, 286.

2. Boghurst, W.; Loimographia, Payne, J. F. ed.; Shaw and Sons: London, 1894.

3. ibid., p. 10.

4. ibid., p. 13.

5. ibid.

6. Van Helmont, J. B.; Ortus medicinae. Id est, initia physicae inaudita (...), Ludovicum Elzevirium: Amsterdam, 1648 (reimpresso por Culture et Civilisation: Bruxelas, 1966), p. 110. Utilizamos, para nossas traduções para o português, também a tradução inglesa dessa obra: Oriatrike or, Physick Refined (...), John Chandler trad., Lodowick Loyd: London, 1662, p. 110.

7. "um gás putrefato da terra".

8. "um espírito selvagem tingido por um veneno". Ambas as citações feitas por Boghurst se referem a Van Helmont, "Tumulus Pestis", in Opuscula medica inaudita, Ludovicum Elzevirium: Amsterdam, 1648 (reimpresso por Culture et Civilisation: Bruxelas, 1966), p. 34; Oriatrike, p. 1102.

9. Ref. 2, p. 14 .

10. Van Helmont, J. B.; Ortus medicinae, p. 106 - 107; Oriatrike, pp. 106 107. Para um estudo do conceito de gás na obra de Van Helmont, vide Porto, P. A.; Van Helmont e o Conceito de Gás - Química e Medicina no Século XVII, EDUC-Edusp: São Paulo, 1995

11. Ref. 2, p. 18

12. ibid., p. 19.

13. ibid., p. 48.

14. (anônimo), The Principles of the Chymists of London, London, 1676, p. 7-8.

15. ibid., p. 11.

16. Para um estudo da analogia entre causas de doenças e um espinho, vide: Niebyl, P.; Bull. Hist. Med. 1971, 45, 5.

17. Porto, P. A.; Quim. Nova 2001, 24, 287.

18. Blancard, S.; The Physical Dictionary, S. Crouch: London, 1697, p. 99.

19. A respeito do que ele chamou de gás da água, Van Helmont afirmou: "É suficiente para mim saber que o gás é uma coisa muito mais sutil ou fina que um vapor, névoa ou oleosidade destilada, embora seja muitas vezes mais espessa que o ar." (Van Helmont, Ortus, p. 73; Oriatrike, p. 69.)

20. Newman, W. R.; Gehennical Fire, Harvard University Press: Cambridge (EUA), 1994.

21. Starkey, G.; Pyrotechny Asserted and Illustrated, R. Daniel: London, 1658, p. 131.
22. Substância que, segundo Van Helmont, seria capaz de transformar todos os corpos em seus respectivos prima entia - um estado em que o corpo estaria purificado, exibindo em sua máxima potencialidade suas virtudes medicinais, mas também transformável em água elementar sem maior dificuldade. Van Helmont descreveu o alkahest com muitos nomes, entre os quais água ígnea e solvente universal. Sobre o alkahest, vide Porto, P. A.; Bull. Hist. Med. 2002, 76, 1.

23. Starkey, G.; Liquor Alchahest, T. R. \& N. T.: London, 1675, p. 21-22.

24. Todos esses processos foram explicados por Van Helmont no tratado "Gas aquae", in Ortus, p. 73-81; Oriatrike, p. 70-77.

25. Notebook of George Starkey 1653 - 1656, Royal Society Manuscript 179, folio $35 \mathrm{v}$.

26. Royal Society - Boyle Letters, vol. 5, folio 135v (carta de Starkey para Boyle, 3 de fevereiro de 1652).

27. Royal Society - Boyle Letters, vol. 5, folio 131r (carta de Starkey para Boyle, 16 de janeiro de 1652).

28. Num adendo ao final da carta, Starkey informou a Boyle que naquele mesmo dia, antes que a carta fosse selada, "sua enorme torta chegou intacta a minhas mãos".

29. Thomson, G.; Loimotomia, or the Pest Anatomized, Nath. Crouch: London, 1666, p. 83. As idéias de Thomson sobre o gás estão discutidas em Porto, P. A.; Quim. Nova 2001, 24, 286.

30. ibid., p. 84.

31. Boyle, R.; The Sceptical Chymist, Everyman's Library, J. M. Dent \& Sons: London, 1949, p. 117; idem, The Works of the Honourable Robert Boyle, Birch, T., ed.; London, 1772, vol. IV, p. 69.

32. Alfonso-Goldfarb, A. M.; Da Alquimia à Química, Nova Stella-EDUSP: São Paulo, 1987, p. 202

33. Vide, por exemplo, Boyle, Works, vol. IV, p. 545.

34. Boyle, Works, vol. III, p. 557.

35. idem, Some Considerations Touching the Usefulnesse of Experimental Naturall Philosophy, 2nd. Part, Hen. Hall: Oxford, 1663, p. 103.

36. Hall, R.; Hall, M. B. eds.; The Correspondence of Henry Oldenburg, University of Wisconsin Press: Madison (WI), e Mansell: London, 1966, vol. 3 , p. 480

37. ibid., p. 483.

38. ibid., p. 485. Oldenburg se refere ao filósofo químico Joachim Polemann, autor de Novum lumen medicum (1647).

39. Harris, J.; Lexicon Technicum or, An universal English dictionary of arts and sciences : explaining not only the terms of art but the arts themselves, Dan. Brown: London, 1704, sub voce.

40. Alfonso-Goldfarb, A. M.; Ferraz, M. H. M.; Quim. Nova 1993, 16, 63; idem, Enlaces 1995, 2, 19; Ferraz, M. H. M.; "A Importância de Stahl", conferência proferida na Faculdade de Ciências da Universidade de Lisboa em 13/05/93; idem, comunicação pessoal. 